\title{
2. Revisar el pasado reciente. Las revistas Criterio y Esquiú y la cuestión de los derechos humanos, 1981-1985'
}

\author{
Mariano David Fabris²
}

\begin{abstract}
Resumen
En este trabajo se abordan las posiciones que asumieron dos revistas católicas, Criterio y Esquiú, en referencia a la revisión del pasado y el procesamiento judicial de las violaciones a los derechos humanos entre 1981 y 1985 . En sus intervenciones es posible rastrear perspectivas políticas, interpretaciones de hechos puntuales y distintas concepciones sobre el vínculo entre lo religioso y lo político en el escenario posdictatorial. En este sentido, siendo revistas católicas, nos preguntamos en qué medida el extendido discurso reconciliador que invocó la jerarquía de la Iglesia y qué obispos, dirigentes políticos y militares utilizaron para reclamar decisiones políticas que cerraran la revisión del pasado, permeó en sus intervenciones. Entendemos que las publicaciones católicas, además de responder a una lógica empresarial y de cultivar determinados vínculos con los lectores, se encuentran en una configuración de poder que incluye a la jerarquía católica y este "polo hermenéutico" debe ser considerado a la hora de analizar sus posicionamientos.

Palabras clave: revistas católicas; democracia; dictadura; derechos humanos; pasado reciente.
\end{abstract}

Revising the recent past. Criterio and Esquiú magazines and the human rights issue, 1981-1985

\begin{abstract}
In this paper we address the positions taken by two Catholic magazines,
\end{abstract}

\footnotetext{
1 Este trabajo fue realizado en el marco de una beca posdoctoral del Consejo Nacional de Investigaciones Científicas y Técnicas.

2 Centro de Estudios Históricos-Universidad Nacional de Mar del Plata/Consejo Nacional de Investigaciones Científicas y Técnicas. Argentina. Correo electrónico: marianofabris76@gmail.com
} 
Criterio and Esquiú, referring to the review of past and the prosecution of human rights violations between 1981 and 1985. In their interventions is possible to trace political perspectives, interpretations of specific events and different conceptions of the link between religion and politics in the post-dictatorship scenario. In this sense, and bearing in mind that these were Catholic magazines we wonder up to what extent their interventions were permeated by a widespread reconciliatory speech that invoked the hierarchy of the Church and bishops, politicians and military leaders used to claim political decision to close the review of past. We understand that Catholic publications, apart from responding to business logics and cultivating certain links with the readers, are immersed in a power configuration that includes the Catholic hierarchy, and this "hermeneutic pole" should be considered when analyzing their positions.

Key words: catholic magazines; democracy; dictatorship; human rights; recent past.

Fecha de recepción de originales: 24/03/2014.

Fecha de aceptación para publicación: 09/04/2015.

\section{Revisar el pasado reciente. Las revistas Criterio y Esquiú y la cues- tión de los derechos humanos, 1981-1985}

En la Argentina de los años ochenta, buena parte de la discusión pública se — dedicó a revisar la experiencia traumática de la década anterior, incluyendo a la violencia política y al terrorismo de Estado y, sobre todo, a definir qué rol le correspondía a la Justicia en esta revisión. La memoria social sobre el pasado reciente se constituyó así como un objeto en disputa entre una multiplicidad de actores. Lo que estaba en juego no era solamente la definición de lo ocurrido, sino la constitución de una configuración política y el lugar que a cada actor le correspondía en ella. ${ }^{3}$ Los medios de comunicación, y en particular la prensa escrita, se convirtieron en un escenario privilegiado de esa disputa: informaron, reflexionaron, asumieron posiciones explícitas, interpelaron a sus lectores con interpretaciones del pasado reciente y buscaron influir en las decisiones de los gobiernos. ${ }^{4}$ En este artículo nos preguntamos de qué forma intervinieron las revistas Criterio y Esquiú, las publicaciones de orientación católica más importantes del período.

\footnotetext{
3 Como señala Vezzetti (2002, p. 193), el espacio de la memoria social "es un campo de lucha en el que los actores reconocidos (o que pugnan por serlo) buscan producir e imponer ciertas visiones en una formación que incluye más ampliamente una representación del presente."

4 Vale recordar que en aquellos años y antes del impacto de las nuevas tecnologías, las revistas y semanarios multiplicaban varias veces su circulación con respecto a los índices actuales.
} 
La revista Criterio apareció en 1928 con el auspicio de intelectuales nacionalistas vinculados a los Cursos de Cultura Católica, y fue dirigida en su primera etapa por Atilio dell'Oro Maini (Rapalo, 1990; Zanatta, 1996). Desde entonces se constituyó como la más destacada publicación católica de actualidad y cultura, atenta a los debates políticos e ideológicos pero también a la producción literaria, el cine, la música, las artes plásticas, la teología, la pastoral de la Iglesia, la historia y la filosofía. ${ }^{5}$ En la década de 1930, de la mano de monseñor Gustavo Franceschi y en un contexto de creciente centralización de la Iglesia católica, la revista adquirió cierto perfil clerical. Este perfil se fue matizando durante la década de 1950 y, bajo la dirección del presbítero Jorge Mejía, Criterio asumió un rol protagónico en la renovación del catolicismo argentino. En el período considerado en este artículo, la dirección fue ejercida por el sacerdote Rafael Braun, quien contó con la colaboración de Carlos Floria, Fermín Fevre, Marcelo Moncerrat, Juan Julio Costa, Natalio Botana y Alberto Petracolla, entre otros. En consonancia con la línea adquirida desde los años del Concilio Vaticano II (1962-1965), Criterio tomó distancia de las perspectivas integristas y mantuvo una autonomía relativa frente a la jerarquía católica.

El semanario Esquiú, por su parte, constituye, muy probablemente, la publicación católica de interés general más leída entre el laicado desde los años sesenta. ${ }^{6}$ La revista fue fundada por los hermanos Luis y Agustín Luchía Puig en abril de 1960, y se editó en forma ininterrumpida hasta 1993. A través de las secciones de política nacional e internacional, economía, espectáculos, deportes, los contenidos dedicados a la mujer y a los niños y el uso de un vocabulario directo, Esquiú pretendió Ilegar a toda la familia con un discurso católico siempre atento a los posicionamientos de la jerarquía eclesiástica.

A lo largo de la década de 1980, ambas revistas tomaron posición en el debate sobre el pasado reciente y respecto del procesamiento judicial de las violaciones a los derechos humanos. En sus intervenciones es posible rastrear perspectivas políticas, interpretaciones de hechos puntuales y distintas concepciones sobre el vínculo entre lo religioso y lo político en el escenario posdictatorial. En este sentido, al tratarse de revistas católicas, resulta interesante

5 La diversidad de temas tratados, la profundidad de los debates suscitados y la calidad de las plumas que nutrieron las páginas de Criterio convirtieron a la revista en un objeto de estudio privilegiado por los investigadores. Entre la bibliografía existente se pueden destacar los trabajos de Rapalo (1990); De Ruschi Crespo (1998); Acha (2000); Rodríguez (2003); Jesús (2007); Borrelli (2012); Pattin y Schkolnik (2013); Lida (2015).

6 Durante sus primeros años tuvo cierto éxito -considerando las estadísticas de circulación-, al aprovechar la demanda de un público ávido de información sobre el Concilio Vaticano II. En 1962, por ejemplo, el promedio de ejemplares por edición fue de 74.500 y se mantuvo en niveles similares hasta el final de la década de 1960, para comenzar a descender luego. En 1974 y 1975 se llegó a los índices de circulación más bajos. Durante los primeros tres años de la dictadura militar se produjo un repunte notable, sin embargo, a partir de 1980, las ventas volvieron a caer. En vísperas del retorno de la democracia el nivel de circulación había descendido a 27.000 ejemplares (Fabris, 2013a, p. 124). 
preguntarse en qué medida el extendido discurso reconciliador que invocó la jerarquía de la Iglesia y qué obispos, dirigentes políticos y militares utilizaron para reclamar decisiones políticas que cerraran la revisión del pasado, permeó en sus intervenciones. Entendemos que las publicaciones católicas, además de responder a una lógica empresarial y de cultivar determinados vínculos con los lectores, se encuentran en una configuración de poder que incluye a la jerarquía católica y este "polo hermenéutico" debe ser considerado a la hora de analizar sus posicionamientos. ${ }^{7}$

Partiendo de estas consideraciones, vamos a sostener que Criterio mantuvo una distancia prudente frente a las posiciones de la jerarquía e incluso reclamó una diferenciación de ámbitos ante la tendencia de los obispos a intervenir directamente en los asuntos políticos. De todas formas, las propuestas de la revista fueron coincidentes con los reclamos de muchos obispos por una amnistía. Criterio buscó presentar como capital su asociación a una tradición republicana que aspiraba a alcanzar una democracia sólida, basada en un conjunto de reglas constitucionales que debían impedir los impulsos autoritarios del último medio siglo. Pero este discurso estuvo tensionado por un "realismo político" que aconsejaba cerrar la revisión del pasado y que se presentaba opuesto al consenso social en torno al juzgamiento de los responsables de las violaciones a los derechos humanos.

Esquiú, a diferencia de Criterio, intentó constituirse como la voz oficiosa de la jerarquía eclesiástica. ${ }^{8}$ Por lo tanto, las posiciones de los obispos tuvieron una mayor incidencia en la revista. Esquiú se sumó entusiasta a la propuesta reconciliadora de la Conferencia Episcopal Argentina (CEA) y, ya en democracia, reclamó un "justo medio" distante de la "la violencia terrorista" y de los "excesos de la represión". A través de esta fórmula intentó transitar del apoyo explícito a la dictadura militar al compromiso con la democracia. Tal como se señaló para el caso del diario católico español Ya, este viraje en el contexto transicional puede derivar en una indefinición política que cuestiona el vínculo con los tradicionales lectores (Pérez López, 2005, p. 69). La defensa del "justo medio" que llevó adelante Esquiú estuvo tensionada por un cambiante escenario político y por el lugar que en él ocupaba la jerarquía de la Iglesia y que decantó con el inicio del juicio a los militares, en la fórmula del "chivo expiatorio". De esta forma, se marginó aquella referencia binaria de la violencia y se hizo hincapié en la responsabilidad de la sociedad en su estallido para

\footnotetext{
7 Mauro (2008,p. 132) define a la jerarquía de la Iglesia como ese "polo hermenéutico total" que coloca a los intelectuales católicos "en una situación siempre precaria". Creemos que, en términos generales, lo mismo se puede decir de la relación que establecen los medios de comunicación.
}

8 Entrevista a Luis Eduardo Luchía Puig, realizada por el autor en julio de 2011. 
sostener -en perfecta coincidencia con la mayoría de los obispos- un pedido reconciliador como dique de contención a los juicios.

En las páginas que siguen abordaremos estas cuestiones en tres apartados. En primer término, centramos nuestro análisis en los años finales de la dictadura. Luego, consideramos la etapa inicial del gobierno democrático de Raúl Alfonsín y observamos los reacomodamientos de las revistas ante el nuevo escenario político. Finalmente, analizamos las posiciones asumidas en el contexto del juicio a los excomandantes.

\section{Las revistas católicas y la "cuestión de los desaparecidos" en los últimos años de la dictadura militar}

Desde 1981, las notas editoriales de Criterio describían un panorama sombrío en el cual reinaba el pesimismo frente a un régimen que consideraba agotado. Sin un horizonte político claro, la situación económica deteriorada aportaba una cuota más de desmoralización a los ciudadanos y creaba una atmósfera insoportable. Para la revista, había llegado la hora de la transición hacia una "república democrática y civilizada". ${ }^{9}$ En 1981, esta preocupación de Criterio por la normalización no incluyó como problema conexo aquello que la prensa de la época llamaba la "cuestión de los desaparecidos". Cuando el tema surgía, esporádicamente, se lo presentaba como una secuela de "la guerra civil". Éste era el núcleo fuerte de la interpretación del pasado reciente desde el cual la revista intervino en un presente que comenzó a cargarse de disputas por el sentido de lo ocurrido. La Argentina habría sufrido una guerra civil que a mediados de los años setenta llegó a su máxima expresión, la sociedad "se militarizó en su lenguaje, en su estilo político, en sus comportamientos", y fue en ese contexto que los militares ocuparon el Estado para "impedir su crisis definitiva" ${ }^{10}$ Para Criterio, la acción de los militares fue legítima porque respondió a una situación de hecho que amenazaba la existencia misma del Estado. Desde esta perspectiva, y aun cuando la revista había sostenido una posición contraria al golpe de Estado de 1976 (Borrelli, 2012), no se puso en duda la necesidad de la "batalla librada contra la subversión".

A partir de la derrota argentina en la Guerra de Malvinas, la principal preocupación de Criterio fue la construcción de un "pacto fundamental" que garantizara la transición a la democracia y que estableciera las bases para

9 Razones para trabajar. (1981, septiembre 10). Criterio, pp. 515-516. Biblioteca de la Universidad Nacional de Mar del Plata (BUNMdP), Mar del Plata.

10 La política no es un juego. (1981, mayo 14). Criterio, pp. 227-229. BUNMdP, Mar del Plata. 
su consolidación. ${ }^{11}$ El reclamo de la revista se centró entonces en la reconciliación. Este concepto, además de tener una larga tradición dentro del pensamiento cristiano, presenta una diversidad de sentidos que favorece su uso extendido en la política. En 1981, el Episcopado había propuesto la reconciliación fundada en el perdón como salida a los enfrentamientos que vivía la sociedad argentina (CEA, 1981, p. 16). Sin embargo, en ese momento, Criterio había expresado reparos ante esa propuesta sosteniendo que si "pensamos [al perdón] en categorías políticas, queda rápidamente asociado a la amnistía, que no solo extingue la culpa sino también la pena merecida por la violación de la justicia, sin siquiera la contrapartida del arrepentimiento" ${ }^{12}$

Un año después, ante la debacle del gobierno militar, Criterio resaltó que era necesaria una "estrategia de reconciliación" porque la "peor manera de volver a la república es escarneciendo a las Fuerzas Armadas". ${ }^{13}$ La conclusión era que había "que aprender a perdonar". ${ }^{14}$ Esta propuesta debía permitir la convergencia cívico-militar para lograr un gobierno constitucional sólido. ${ }^{15}$ De todas formas, la revista defendió una traducción política de la reconciliación sin "los procedimientos del eufemismo y del doble sentido" que caracterizaron al discurso de los obispos sobre esta cuestión. ${ }^{16}$ El valor de la reconciliación expresó toda su potencialidad política como "restitución de la unidad nacional". ${ }^{17}$

La posición que asumió Criterio, en un escenario político dominado por la incertidumbre, se sustentó sobre una hipótesis que indicaba que la consolidación de un futuro régimen democrático, objetivo fundamental que relegaba cualquier otro, solo se lograría abandonando la idea de revisar el pasado: "pensando en la instalación y consolidación del régimen que se quiere nuevo y no en la venganza por método y por actitud de espíritu". ${ }^{18}$

11 Después de la derrota. (1982, junio 24). Criterio, p. 297. BUNMdP, Mar del Plata.

12 La palabra de nuestros obispos. (1981, julio 23). Criterio, p. 409. BUNMdP, Mar del Plata.

13 Una estrategia de reconciliación. (1982, julio 8). Criterio, p. 330. BUNMdP, Mar del Plata.

14 Superar la crisis. (1982, julio 8). Criterio, p. 473. BUNMdP, Mar del Plata.

15 La convergencia cívico militar. (1982, septiembre 23). Criterio, p. 511. BUNMdP, Mar del Plata.

16 En otro lado hemos sostenido que, precisamente, en torno a la idea de reconciliación operó lo que Bourdieu y de Saint Martín (2009, p. 151) llaman el "eufemismo y el doble sentido" para caracterizar la "eficacia simbólica" del discurso episcopal (Fabris, 2012, p. 94).

17 Santagada, O. (1982, septiembre 9). Deberes y tareas para la Unidad Nacional. Criterio, pp. 526-527. BUNMdP, Mar del Plata.

18 El caso de los jueces. (1983, abril 28). Criterio, p. 148. BUNMdP, Mar del Plata. 
Previamente a abandonar el gobierno, las Fuerzas Armadas (FFAA) dieron a conocer el "Documento final sobre la guerra contra la subversión y el terrorismo", en el cual se caracterizaba a las acciones represivas como actos de servicio, y promulgaron la Ilamada "Autoamnistía". ${ }^{19}$ Desde las páginas de Criterio se sostuvo que el "Documento final" "no menciona lo que todos saben: que un gran número de personas 'desaparecieron' luego de haber sido detenidas por las fuerzas de seguridad". De todas formas, la revista matizó su crítica al documento al afirmar que muchos esperaban una confesión pública pero que "ningún sector político, sindical, empresario, eclesial o cultural, ha realizado institucionalmente una autocrítica". ${ }^{20}$ Frente a la "Autoamnistía", la revista mantuvo un posicionamiento similar. Si bien reconoció que esa medida promulgada por los propios interesados estaría viciada desde su origen, también se preguntó si no había llegado el momento de "cortar la cadena de los resentimientos" y propuso que la clase política apartara:

"el tema de la polémica preelectoral, comprometiéndose a debatir una ley de amnistía prudente y realista tan pronto comience el nuevo régimen constitucional, e invitando a los jefes militares que encabezaron el régimen en sus diferentes etapas a asumir desde ahora la responsabilidad de las órdenes de guerra cuya ejecución cobró víctimas que murieron en su ley, otras que en ambos bandos sufrieron la atrocidad de la lucha, en una sociedad que cayó...en la responsabilidad colectiva del silencio por miedo o por objetiva inseguridad". ${ }^{21}$

Un aspecto interesante del debate sobre la amnistía fue que el gobierno militar buscó el apoyo de los obispos para su proyecto pero no obtuvo un resultado favorable. Criterio aplaudió la prescindencia de la CEA, aunque reconoció que no estaba claro si esa actitud se debía a una convicción de los obispos, según la cual no les correspondía a ellos intervenir en una cuestión eminentemente política, o solo a la falta de acuerdo sobre el contenido y los alcances de la medida proyectada por el gobierno. ${ }^{22}$ Más adelante quedaría claro que se trataba de esta última opción.

En el caso de Esquiú, los años de la debacle militar constituyeron un período de reacomodamiento más complejo. A diferencia de Criterio, el

\footnotetext{
19 Clarín, 29 de abril de 1983, p. 2. Archivo Municipal Roberto T. Barili (AMRB), Mar del Plata.

20 Un tiempo para callar. (1983, mayo 12). Criterio, p. 183. BUNMdP, Mar del Plata.

21 El debate sobre la amnistía. (1983, agosto 11). Criterio, p. 403. BUNMdP, Mar del Plata.

22 Paso atrás. (1983, agosto 23). Criterio, p. 438. BUNMdP, Mar del Plata.
} 
semanario de Luchía Puig cultivaba un vínculo estrecho con el Episcopado y había apoyado explícitamente al gobierno militar. Esta identificación no presentó mayores problemas hasta 1981, pero a partir de entonces su alineamiento se dificultó porque la jerarquía eclesiástica comenzó a tomar una distancia prudente frente al gobierno, por lo menos, a través de sus documentos colectivos más importantes. Para superar esta tensión, Esquiú asumió un compromiso pleno en la defensa de la fórmula reconciliadora que los obispos sostuvieron frente a la cuestión de los desaparecidos. El fuerte respaldo de la revista al Ilamado reconciliador permitía cerrar aquella tensión, profundizando la identificación con la jerarquía. Era, al mismo tiempo, una forma no traumática de dar vuelta la página de la historia levantando la bandera de la unidad nacional frente a las voces que pretendían revisar la actuación de los militares. En el caso de Esquiú, el "doble sentido" del discurso eclesial funcionaba plenamente.

Antes de que este pedido reconciliador ocupara las páginas de Esquiú, la revista le otorgó un apoyo cerrado al gobierno militar y les negó entidad a las voces que desafiaban al consenso castrense, reiterando las denuncias sobre la "campaña antiargentina". En marzo de 1981, por ejemplo, publicó una nota del columnista invitado José Luis Atienza bajo el título "¿Qué son los derechos humanos?", en la cual se rechazaba la concepción de los derechos humanos en nombre de los derechos naturales dados por Dios y agregaba "en lo que hayamos hecho mal...somos responsables. Y en lo que haya sido defensa personal -derecho natural que también tenemos- cada cual sabrá discernir por qué razón en el mundo entero pocos nos entendieron" ${ }^{23}$

A lo largo de 1981, las notas de opinión firmadas bajo el seudónimo de "Centinela" reforzaron el apoyo a las autoridades castrenses. En una de sus intervenciones aplaudió al por entonces jefe del Ejército, Leopoldo Galtieri, quien había asegurado que no aceptarían ninguna revisión sobre la "guerra sucia". La nota ofreció además una serie de reflexiones acordes con el pensamiento castrense:

\begin{abstract}
"siempre es bueno recordar el sacrificio de quienes inmolaron sus vidas para que los argentinos, hoy, podamos vivir en libertad...Los argentinos debemos estar orgullosos de nuestras Fuerzas Armadas, que supieron defender el derecho que teníamos de seguir viviendo en el sistema que elegimos desde los albores de la Patria...Y si nuestro país está de pie junto a los que no admiten la esclavitud marxista, es por derecho propio. Por ese derecho ganado por un pueblo que no quiso ser esclavo y que para ello tuvo héroes anónimos y mártires como los que recordó el Ejército Argentino. Sus nombres y el derecho a vivir no habrán de
\end{abstract}

23 Atienza, J. L. (1981, marzo 29). ¿Qué son los derechos humanos? Esquiú, p. 17. Biblioteca del Congreso de la Nación (BCN), Buenos Aires. 
figurar nunca en las listas de quienes reclaman con fines ocultos los principios de los derechos humanos, derechos que no dudamos deben ser inviolables para los que luchan, verdaderamente, por su libertad". ${ }^{24}$

En definitiva, la "cuestión de los desaparecidos" no era más que un "un caballito de batalla de buena parte de la oposición [y] de la campaña contra el país que se registra en el exterior" ${ }^{25}$

La guerra de Malvinas y la derrota argentina no parecieron modificar ni la valoración que la revista hacía del gobierno militar ni su visión del tema de los derechos humanos. En este período, el jefe de redacción, Héctor Simeoni, asumió la resistencia a la revisión de lo ocurrido desde 1976. Con este propósito negó los casos de violaciones a los derechos humanos que comenzaban a salir a la luz y actualizó el discurso castrense sobre los peligros que acechaban a la Nación. Simeoni informó sobre el supuesto regreso "de la guerrilla marxista a nuestro país" y se preguntó si "nos encontraría bien parados mañana o pasado un reinicio de la 'acción directa' de los chicos de Firmenich" ${ }^{26}$

Posteriormente, este discurso de tono castrense fue marginado en beneficio de un reclamo reconciliador a tono con los planteos episcopales. Para Álvarez Lijó había que "recordar los errores" pero "extender el perdón que favorece la convivencia y lleva, con un sello de caridad, a la reconciliación anhelada". ${ }^{27}$ Por el contario, "inquirirlos con ánimo de revancha solo puede acentuar los enconos y dificultar el entendimiento". Frente a ello, la reconciliación planteada por los obispos era la única alternativa. ${ }^{28}$ La revista seguía el mismo camino trazado por la jerarquía desde 1981 y miraba la política desde una pretendida posición de exterioridad hablando en términos de "antinomias", "guerrilla", "represión" o "desaparecidos" para hacer referencia a hechos ocurridos en un escenario distante.

La traducción que hizo Esquiú de las propuestas de la CEA explicitó políticamente lo sostenido por los obispos: "No basta señalar errores...no basta denunciarlos: hay que perdonarlos". ${ }^{29}$ Frente al "Documento final" y la ley de Autoamnistía, desde las páginas de Esquiú se insistió en la necesidad de

\footnotetext{
24 Centinela (1981, abril 26). Después de la guerra. Esquiú, p. 6. BCN, Buenos Aires.

25 Álvarez Lijó, M. (1982, febrero 28). Homogeneidad y pluralismo. Esquiú, p. 8. BCN, Buenos Aires.

26 Simeoni, H. (1982, noviembre 21). Por favor, ¿me da fuego? Esquiú, p. 3. BCN, Buenos Aires.

27 Álvarez Lijó, M. (1982, julio 18). Comienza la hora del revisionismo. Esquiú, p. 8. BCN, Buenos Aires.

28 ¿Tiempo de "revancha"? (1982, agosto 8). Esquiú, p. 4. BCN, Buenos Aires.

29 Álvarez Lijó, M. (1982, noviembre 14). Concertando para la reconciliación. Esquiú, p. 8. BCN, Buenos Aires.
} 
la reconciliación, asimilando las decisiones gubernamentales a las propuestas episcopales en una lectura que ni los propios obispos lograron consensuar. Para Álvarez Lijó:

"así como no se busca la muerte del pecador, sino que se convierta y viva, así, más que la persecución de victimarios, lo que se ansía es el consuelo de las víctimas y con ello la reconciliación de cuantos se enfrentaron en la lucha". ${ }^{30}$

Sin embargo, representar la propuesta episcopal no fue sencillo porque entre los prelados no existió un sentido unívoco de la reconciliación, y recrearlo suponía aventurarse en un camino sinuoso donde inevitablemente se deberían omitir algunas voces. Frente a esta situación, la revista eligió reflejar la diversidad de posiciones que podían reconocerse al interior de la CEA y luego sentó su propia perspectiva con mayor autonomía. ${ }^{31}$ Desde su columna, Gerardo Palacios Hardy apuntó a "estos fiscales que se han rasgado las vestiduras"; manifestó su preocupación de que se "quiera reducir todo el drama de la subversión a un solo capítulo: el del método que se utilizó para combatirla"; y concluyó que "los padres que hoy lloran a sus hijos tendrían que preguntarse dónde estaban ellos mismos mientras el veneno hacía su efecto".$^{32}$

Álvarez Lijó formuló una moderada crítica a la metodología represiva, pero enfatizó que la "vulneración, real o supuesta, de los derechos humanos, empañó la imagen argentina en asambleas y congresos, y llevó a grupos radicalizados a politizar el problema". Con respecto al documento de la Junta, entendió que era necesario porque "Ios censores de las FFAA marginan el origen de la represión" ${ }^{33}$ Frente a la Ilamada Autoamnistía militar, un editorial resaltó que en el documento "Iglesia y Comunidad Nacional" los obispos insistieron en la reconciliación con base en la verdad, la justicia y el amor y de esta forma se volvió a equiparar el reclamo eclesiástico con las decisiones gubernamentales. ${ }^{34}$

Sin embargo, como ya había ocurrido con el documento anterior, no

\footnotetext{
30 Álvarez Lijó, M. (1983, abril 3). Otros candidatos ante la amnistía. Esquiú, p. 8. BCN, Buenos Aires.

31 La revista reprodujo el rechazo manifiesto de Hesayne, la aprobación entusiasta de Plaza o Quarraccino y valoraciones intermedias como las de Laguna o Cándido Rubiolo. Esquiú, 18 de mayo de 1983, p. 3. BCN, Buenos Aires.

32 Palacios Hardy, G. (1983, mayo 18) Los capítulos del drama. Esquiú, p. 2. BCN, Buenos Aires.

33 Alvarez Lijó, M. (1983, mayo 18). Racconto en el documento sobre los desaparecidos. Esquiú, p. 8. BCN, Buenos Aires.

34 Hacia una amnistía efectiva. (1983, agosto 7). Esquiú, p. 16. BCN, Buenos Aires.
} 
hubo espacio entre los obispos para sentar una posición común y poco después la revista debió informarlo a través de las palabras del secretario de la CEA, Carlos Galán, quien afirmó que frente a la amnistía, "los obispos, particularmente podrán opinar, como cualquier cristiano; pero no será la palabra oficial de la Iglesia". ${ }^{35}$

\section{El retorno de la democracia y los "dos demonios"}

Con el retorno de la democracia se inició un período cargado de desafíos para las revistas católicas. La jerarquía eclesiástica, señalada como cómplice de la dictadura, y el rechazo social a cualquier lectura indulgente con las FFAA, pusieron en cuestión antiguos compromisos e interpretaciones. Si Criterio mostró mayor continuidad en sus posicionamientos, el itinerario de Esquiú expuso vaivenes e intentos de reacomodamiento que, entendemos, complicaron su vínculo con los lectores.

Inicialmente, las revistas católicas aprobaron la propuesta alfonsinista de revisión del pasado sustentada en el enjuiciamiento de las cúpulas castrenses y guerrilleras. Según se sostenía en Criterio:

\footnotetext{
"Se atacaron pues dos frentes: el militar y el de la subversión terrorista. El proceso a los montoneros, la derogación de la autoamnistía y las reformas al Código de Justicia Militar se ubican en esta línea. El gobierno apostó a favor de una línea moderada que no renuncia al deber de aclarar la verdad acerca de los años ciegos de la violencia recíproca y de hacer justicia" ${ }^{36}$
}

Estas decisiones del gobierno representaban, desde la óptica de la revista, una búsqueda de equilibrio fundamental para la consolidación de la democracia y el distanciamiento de los enfrentamientos de los años setenta. Por eso, Criterio calificó como "respuestas jacobinas de los justicieros" las interpretaciones que reclamaron otras vías de abordaje judicial del pasado reciente. ${ }^{37}$ Desde la revista dirigida por Rafael Braun se argumentó que, en función de la consolidación de la democracia, no se debía entrar en desafíos abiertos con un factor de poder como las FFAA. La revisión del pasado era un tema que se debía manejar cuidadosamente.

\footnotetext{
35 Noce, M. (1983, agosto 21). Ley de amnistía: materia opinable para la Iglesia. Esquiú, p. 11. BCN, Buenos Aires.

36 Decisiones cruciales. (1984, marzo 22 ) Criterio, p. 75. BUNMdP, Mar del Plata.

37 Decisiones cruciales. (1984, marzo 22). Criterio, p. 75. BUNMdP, Mar del Plata.
} 
Si bien Criterio compartió la pretensión de equilibrio que defendía el gobierno, acompañó su condena a los "dos demonios" con una crítica a la sociedad por su responsabilidad en la legitimación de la violencia como medio válido para dirimir las diferencias políticas. Estas referencias se hicieron recurrentes a medida que avanzó el procesamiento judicial de los militares. Para la revista, los "dos demonios" no podían ocultar la complicidad de una sociedad en la que anidaban el autoritarismo y la falta de respeto por las normas constitucionales. En todo caso, se aceptaba la hipótesis simplista de los "dos demonios" si era útil para salvar a las instituciones convirtiéndose en un relato sobre el pasado obturador de la discusión. Por eso, si bien era "preciso desnudar el infierno secreto sobre el cual vivimos tantos años", no se debía "persistir en nuestra actitud suicida que trae al pasado hacia el presente para dirimir conflictos y dividir al mundo, según dictados de ocasión, en réprobos y elegidos". ${ }^{38}$

Con la misma prevención la revista valoró el trabajo realizado por la Comisión Nacional sobre la Desaparición de Personas (CONADEP), pero encendió una luz de alarma por las consecuencias que podría tener en una sociedad movilizada por el pasado reciente. Criterio reclamó "prudencia" a una justicia que debería tener límites y a una clase política a la que le correspondía señalar el "sentido de esos límites más allá de los cuales toda la sociedad entraría de nuevo en el estado de naturaleza" ${ }^{39}$ Ya tempranamente Criterio apostó por una amnistía:

\begin{abstract}
"Se han reducido penas a los delincuentes comunes -con los desastrosos resultados conocidos-, hay un proyecto con media sanción del Senado para liberar de hecho a los presos 'políticos', hay manifestantes en la calle que -suprema paradoja- en nombre de los derechos humanos piden la libertad de Firmenich, pero nadie ha reclamado una amnistía general que cierre un ciclo negro de nuestra historia y libere nuestras energías para construir el futuro en vez de petrificarnos, como la mujer de Lot, en la morbosa investigación del pasado"..$^{40}$
\end{abstract}

Esquiú, por su parte, defendió la idea del "justo medio" que, al igual que el equilibrio reclamado por Criterio, se constituyó como un espacio de neutralidad y distanciamiento frente a la "subversión" y a los "excesos de la represión". Sin embargo, existen dos particularidades que distinguen al semanario de los

38 Decisiones cruciales. (1984, marzo 22). Criterio, p. 75. BUNMdP, Mar del Plata.

39 Los crímenes y la memoria. (1984, octubre 11). Criterio, p. 542. BUNMdP, Mar del Plata.

40 Justicia, reconciliación y amnistía. (1984, noviembre 11). Criterio, p. 619. BUNMdP, Mar del Plata. 
Luchía Puig. En primer lugar, esta interpretación buscó respaldarse siempre en la actitud que había asumido la jerarquía católica. En segundo lugar, la posición equidistante que intentó asumir Esquiú implicaba tomar distancia de una experiencia dictatorial a la que había apoyado explícitamente tiempo antes. ${ }^{41}$ Este corrimiento hacia el "justo medio" fue una respuesta a la necesidad de asumir posiciones políticas a tono con el nuevo espíritu democrático, pero puso en cuestión sus vínculos con los antiguos lectores.

Siguiendo la nueva línea editorial, Esquiú apoyó los decretos de enjuiciamiento firmados por Raúl Alfonsín en diciembre de 1983 que, como se recordará, incluían tanto a los líderes procesistas como a los de la guerrilla. Igualmente, ya desde ese momento se afirmó que la labor de la justicia no debía contaminarse con un espíritu de venganza. Como sostuvo Álvarez Lijó "mientras no haya espíritu de odio o de desquite, de persecución o de venganza, todo está muy bien". ${ }^{42}$ Agustín Luchía Puig, uno de los directores de la revista, destacó las declaraciones del presidente cuando éste sostuvo que "se ha pretendido combatir el demonio con el demonio (la violencia con la violencia) convirtiendo al país en un infierno", y afirmó "muy bien Sr. Presidente, solo la impiedad y el demonio dejarán de aplaudirle". ${ }^{43}$

El último número de Esquiú de abril de 1984 condensó las tensiones que cruzaban al semanario en el nuevo contexto político. En la tapa se representó a un grupo de Madres de Plaza de Mayo orando reunidas en torno a una cruz. Anticipando alguna reacción de sus lectores, se ofreció una explicación de la imagen elegida:

\begin{abstract}
"No es la primera vez, ni será la última, que Esquiú se ocupa de las Madres de Plaza de Mayo. Hemos sido comprensivos con su dolor pero no vacilamos en señalar la instrumentación política que circundaba sus acciones. Tampoco podemos dejar de reconocer su papel protagónico como despertadoras de la conciencia del país sobre un tema que muchos prefieren soslayar: las violaciones a los derechos humanos. Tanto las cometidas por los subversivos como las todavía más graves, por provenir de quienes debieron dar ejemplo, perpetradas por aquellos que se excedieron en la represión". ${ }^{44}$
\end{abstract}

\footnotetext{
41 A modo de ejemplo, cuando Videla dejó el gobierno en 1981, los responsables de la revista lo despidieron con una emotiva "Carta para un general que se va", Esquiú, 29 de marzo de 1981, p. 3. BCN, Buenos Aires.

42 Álvarez Lijó, M. (1983, diciembre 25). Juicio a terroristas y ex miembros de la Junta. Esquiú, p. 5. BCN, Buenos Aires.

43 Luchía Puig, A. (1984, enero 22). De demonios e impiedades. Esquiú, p. 5. BCN, Buenos Aires.

44 Nuestra portada. (1984, abril 29). Esquiú, p. 2. BCN, Buenos Aires.
} 
La cita expresa varias de las posiciones que había asumido Esquiú en los últimos años, pero ahora eran incorporadas a un relato con el que se pretendía marcar el distanciamiento de la revista frente el espacio conflictivo de la transición. En las páginas de Esquiú, no era nueva la idea de instrumentación política de las Madres, por el contrario, era el lugar desde donde la revista las observó, en una mirada plagada de desconfianza. Junto a esta denuncia de los "intereses políticos" se incluía el reconocimiento de los "excesos" situados al mismo nivel que las acciones de la guerrilla. El final de la explicación de esa tapa sintetiza las contradicciones: "así como el histórico madero, de instrumento de tortura se transformó en símbolo de redención, quisiéramos que la justicia divina troque en resignación el resentimiento que todavía pueda albergar su corazón". ${ }^{45}$

Con esta posición la revista rompió, en parte, con su pasado reciente, lo que resultó en una indefinición política de cara a sus lectores. Con anterioridad se había abordado la cuestión desde las ideas propias del régimen castrense: "la reacción ante el ataque a los valores occidentales", "la campaña anti-argentina", "la instrumentación política de las Madres", entre otras, formaban parte del credo dominante en la revista. ¿Hasta qué punto el lector que se identificaba con estas ideas estaba dispuesto a acompañarla hacia su nueva posición de "justo medio"? Las cartas que llegaron a la redacción ofrecen algunas respuestas. En una de ellas se sostenía que "esas madres del dichoso pañuelito...se prestan para la clásica ronda respaldadas por dólares" y concluía "disculpen, pero el que calla otorga y esa tapa enferma". ${ }^{46}$

Más tarde, otra carta insistió en el tema:

"últimamente dedicaron páginas a todo color y amplia difusión para las Madres de Plaza de Mayo, para el premio Nobel Esquivel y para dos obispos [De Nevares y Novak] que parecen ser la única voz de la Iglesia...Las Madres de Plaza de Mayo no nos representan a todas las madres que sentimos dolor...Cuidemos este periódico que hasta ahora no creaba sectarismos que dividen". ${ }^{47}$

La revista respondió: "Nos parece que el sano justo medio ha sido olvidado por usted". ${ }^{48} \mathrm{El}$ "justo medio" exponía a la revista a las críticas de aquellos lectores que se habían identificado con sus posiciones políticas en el pasado, cuando

\footnotetext{
45 Nuestra portada. (1984, abril 29). Esquiú, p. 2. BCN, Buenos Aires.

46 Las Madres de Plaza de Mayo. (1984, mayo 20). Esquiú, p. 12. BCN, Buenos Aires.

47 Algo más sobre 'Las Madres de la Plaza'. (1984, agosto 19) Esquiú, p. 12. BCN, Buenos Aires.

48 Algo más sobre 'Las Madres de la Plaza'. (1984, agosto 19) Esquiú,p. 12. BCN, Buenos Aires.
} 
no creaba "sectarismos que dividen", pero también de quienes, en el amanecer de la democracia, le recordaban a Esquiú sus habituales elogios a Videla:

\begin{abstract}
"No sé qué impresión les habrá causado rememorar estas ideas; espero que vergüenza y arrepentimiento ante la imperdonable ceguera que padecían. Si no es así, debo lamentar mucho que un medio de prensa de la magnitud de Esquiú esté dirigido y redactado por simples, vulgares y despreciados golpistas". ${ }^{49}$
\end{abstract}

La revista pretendió ocupar una posición equidistante, a riesgo de caer en la indefinición política, en momentos en que el conflicto entre relatos beligerantes del pasado reciente se profundizaba con la llegada de la democracia.

\title{
Los juicios, la sociedad y la responsabilidad colectiva bajo la óptica de Criterio y Esquiú
}

Desde finales de 1984, de ambas revistas fue desapareciendo la preocupación por el "equilibrio" o el "justo medio" y la mayoría de sus intervenciones se centraron en el papel de la sociedad en el pasado reciente. Este planteo remite a la "responsabilidad colectiva" en la legitimación del terrorismo de Estado que, como señala Vezzeti (2002, p. 40), se incorporó en forma recurrente a pedidos de reconciliación que diluían las responsabilidades concretas en una genérica culpabilidad social.

Criterio reforzó su crítica a la sociedad a la que, de ninguna manera, consideró víctima inocente de los enfrentamientos entre los "extremos". La revista no ignoró el carácter polémico de la idea de "responsabilidad colectiva" pero sostuvo que se podía hablar de una "suerte de falta colectiva del respeto por los medios y del respeto por el hombre". Desde esta perspectiva, con el juicio a los excomandantes "la catarsis habrá producido sus frutos y habrá llegado el momento de sancionar responsabilidades directas y de reconocer complicidades indirectas. Y desde esta lección de una historia sombría, evitar la venganza y homologar la reconciliación necesaria". ${ }^{50}$ La opción por el cierre de la discusión sobre el pasado reciente se justificó en un "realismo político" que desaconsejaba mantener abiertas "heridas" que tarde o temprano habrían de "erosionar a las instituciones". ${ }^{51}$

\footnotetext{
49 Contra Videla. (1984, marzo 18). Esquiú, p. 10. BCN, Buenos Aires.

$50 \mathrm{El}$ juicio. (1985, mayo 23). Criterio, p. 223. BUNMdP, Mar del Plata.

51 Un nuevo mapa político. (1985, julio 27). Criterio, p. 363. BUNMdP, Mar del Plata.
} 
Durante el segundo semestre de 1985, mientras se desarrollaba el juicio a las Juntas, Criterio volvió a señalar a la sociedad por su papel en el pasado reciente. Según interpretaba, en la Argentina de los años setenta "gran parte de la sociedad se fue haciendo insensible a la distinción entre los medios aceptables en política". Se produjo "un agravamiento del relativismo moral, cuando no del miedo que envilece, o del cinismo individual, sectorial, colectivo". En consecuencia, "para la mayoría de la sociedad civil el juicio público es parte necesaria de un acto de contrición que debería ser colectivo". ${ }^{52}$

Luego de estas afirmaciones, y en paralelo al desarrollo de los tramos finales del juicio, el tema desapareció de las páginas de Criterio. Si bien es riesgoso aventurar una explicación sobre esta ausencia, se debe tener muy en cuenta que el ánimo social era, en el contexto del juicio, renuente a cualquier interpretación que relativizara la responsabilidad de los militares. Criterio no se estremeció ante los relatos de los testigos ni se movilizó ante la sentencia, pero evitó, en aquel momento, interpelar a sus lectores con una interpretación diferente.

Esquiú asumió una posición similar. A lo largo de la segunda mitad de 1984 abandonó la idea del "justo medio" para sostener que los militares enjuiciados por la violación a los derechos humanos eran el "chivo expiatorio" que cargaba con las culpas de toda la sociedad. Este nuevo giro en los posicionamientos de la revista era resultado de una conjunción de situaciones: del informe de la CONADEP -al que se entendía como poco equilibrado-, de la certeza de que la revisión del pasado tendría una instancia judicial con alcance incierto y del señalamiento de complicidades eclesiales con la dictadura. ${ }^{53}$ En este sentido, la inclusión del nuncio apostólico Pio Laghi entre los hombres de la Iglesia vinculados al último régimen militar marcó un punto de inflexión. Era el representante del Vaticano y su caso motivó una defensa sin fisuras del Episcopado argentino. Esquiú fue un canal de transmisión de ese apoyo, e incluso publicó una entrevista al exnuncio donde rechazaba de plano la acusación. Además, en el mismo número, una columna de Luis

52 Justicia y política. (1985, agosto 8). Criterio, p. 400. BUNMdP, Mar del Plata.

53 En septiembre el Consejo Supremo de las Fuerzas Armadas, primera instancia judicial en la revisión del pasado, dictaminó que "el accionar militar contra la subversión terrorista" había sido "en cuanto contenido y forma, inobjetable", y de esta forma aceleró los pasos para que la justicia civil se hiciera cargo del procesamiento de las juntas del proceso. Clarín, 26 de septiembre de 1984, p. 45. AMRB, Mar del Plata. Poco después, la revista El Periodista dio a conocer una supuesta lista secreta de la CONADEP que contenía los nombres de los implicados en la violación a los derechos humanos según los relatos de los testigos. En la lista se incluyó al exnuncio apostólico Pío Laghi, a monseñor Antonio Plaza, a monseñor Blas Conrero, arzobispo de Tucumán -fallecido en julio de 1982- y a una decena de sacerdotes. Clarín, 4 de noviembre de 1984,p. 4. AMRB, Mar del Plata. 
Saavedra abordó el tema avizorando que el destino final sería "Un Nüremberg Porteño". ${ }^{54}$ La revista reclamó "Justicia sin show" y recordó que la:

"agresividad hacia las FFAA, por parte de dirigentes izquierdistas, integrantes de asociaciones defensoras de los derechos humanos y prensa demagógica, visible siempre, se ha agudizado, paradójicamente, desde que el gobierno constitucional, atento a sus denuncias ha facilitado a la justicia las investigaciones pertinentes". ${ }^{55}$

Con el inicio del juicio se reforzó el argumento de que la acción de los militares, aun con "excesos", había posibilitado el retorno de la democracia. Además, se puso en el centro a la reconciliación y se concluyó que los militares, a través del juicio, expiaban las culpas de toda la sociedad. Nuevamente, Luis Saavedra planteó esta idea al preguntarse si " ¿No estaremos buscando un chivo expiatorio para las culpas de toda la sociedad en la guerra sangrienta que enlutó a la Nación?", y señaló a los "terroristas" y a los padres "que no advirtieron a tiempo que los hijos tomaban la senda irreversible de la violencia". ${ }^{56}$

Se podría decir que la revista puso en el banquillo de los acusados a la sociedad, invirtiendo la lógica de la teoría de "los dos demonios" que pretendía concentrar las "culpas" en la guerrilla y en los militares obviando la discusión sobre la responsabilidad social. Una sociedad, en las palabras de Luis Luchía Puig, "enferma de violencia" que apañó "la furia subversiva" destinada a "establecer en la Argentina una dictadura marxista" y que luego respaldó "la enérgica y sacrificada intervención de las fuerzas armadas". Por eso el director de Esquiú reclamó que no se cayera en la "hipocresía de buscar 'chivos expiatorios' de culpas que a todos, en mayor o menor grado, nos toca compartir". ${ }^{57}$ Poco después profundizó esta idea:

"Los hechos denunciados son horrendos. Pero, ¿hasta qué punto cabe responsabilidad total y única a los acusados?...La realidad es que las fallas fueron de

54 Saavedra, L. (1984, noviembre 11). Sobre 'héroes' y tumbas. Esquiú, p. 2. BCN, Buenos Aires.

55 Justicia sin show. (1985, marzo 17). Esquiú, p. 8. BCN, Buenos Aires.

56 Saavedra, L. (1985, mayo 5). ¿Definitivamente nunca más? Esquiú, p. 6. BCN, Buenos Aires.

57 Luchía Puig, L. (1985, mayo 12). El fin y los medios. Esquiú, p. 3. BCN, Buenos Aires. 
todos. De quienes las cometieron y de quienes las toleraron o no las denunciaron con rigor. Ese fue el cuadro de culpabilidad colectiva con que se encontró el gobierno al asumir". ${ }^{58}$

Resulta difuso el límite entre un reclamo para que la sociedad se mirara a sí misma revisando aquellas actitudes que, si no fueron suficientes, por lo menos sí necesarias para que la represión asumiera los contornos de una verdadera masacre y una interpretación del pasado que busca diluir las responsabilidades concretas de los hechos juzgados en una genérica culpabilidad social. ${ }^{59} \mathrm{Y}$ es en ese espacio difuso donde la revista se ubicó para mantener la pretensión representativa de un "justo medio" que recuerda a cada paso que la ola de violencia no se inició en 1976, sino con el secuestro de Aramburu, seis años antes.

Al considerar el resultado final del juicio desde esta perspectiva, la revista realizó un balance que puso en un segundo plano las condenas a los excomandantes y volvió a morigerar sus responsabilidades orientando su mirada a la sociedad. Según Luchía Puig, el juicio a los excomandantes tenía lugar porque, en su momento, la justicia no había hecho caer "el peso de la ley sobre la subversión" ${ }^{60}$ Aseguró además que en el juicio habían pesado más las consideraciones políticas o morales por sobre las jurídicas y que, consecuentemente, era el momento de refrescar la memoria sobre las causas de la "guerra sucia". Con las condenas -y también con las absoluciones- en el centro de la escena política, Luchía Puig hizo su aporte en la disputa por la construcción de una memoria social sobre el pasado reciente a partir de una interpretación de lo sucedido que se centró en la responsabilidad de los grupos guerrilleros que intentaron "establecer una dictadura marxista". Solo la intervención de los militares avalada por la sociedad evitó que nuestro país fuera "un eslabón más

\footnotetext{
58 Luchía Puig, L. (1985, octubre 9). Los chivos expiatorios. Esquiú, p. 3. BCN, Buenos Aires. Esta argumentación, que trasladaba la responsabilidad a la sociedad, en cierta forma coincidía con los planteos de los exmiembros de las juntas militares durante el juicio iniciado en abril de 1985. A modo de ejemplo se pueden considerar las expresiones del exbrigadier general Basilio Lami Dozo ante los jueces federales: "Si la guerra es irracional, señor presidente, también es irracional la actitud de la sociedad argentina, cuando primero lanza a sus Fuerzas Armadas a la guerra y después, cuando disfruta de los beneficios de la victoria, se horroriza por reales o supuestos excesos. Pienso que este juicio, más que un proceso a las juntas militares, debería serlo a la veleidosa sociedad argentina”. Clarín, 22 de octubre de 1985, p. 2. AMRB, Mar del Plata.

59 En la conceptualización de la represión ilegal como masacre o exterminio planificado seguimos a Hugo Vezzetti (2002, p. 159), quien utiliza estos conceptos distinguiéndolos del genocidio. Según el autor, mientras "en las masacres las víctimas son elegidas por lo que hacen o piensan (o por lo que se cree que piensan y lo que se teme que puedan hacer), la lógica del exterminio genocida es que la víctima es elegida solo por lo que es sin ninguna posibilidad de elegir o actuar para evitar su destino".
}

60 Luchía Puig, L. E. (1985, diciembre 22). Que el cielo los juzgue. Esquiú, p. 5. BCN, Buenos Aires. 
de la ya extensa cadena de naciones sojuzgadas por el comunismo". Si bien reconocía la ilicitud de los métodos represivos aplicados, finalizó recordando, una vez más, que la "tremenda responsabilidad moral de la sociedad argentina" tenía "en los sentenciados sus chivos expiatorios" ${ }^{61}$

\section{Conclusión}

En este artículo nos propusimos indagar de qué forma dos publicaciones de tradición católica intervinieron en una discusión sobre la violencia política y la represión de los años setenta y sobre su procesamiento judicial con el retorno de la democracia. El interés por este tema surgió en trabajos previos, donde pudimos observar que la jerarquía de la Iglesia jugó un rol protagónico en esa discusión y que principios de onda raíz católica, como el del perdón y la reconciliación, fueron utilizados en forma recurrente por funcionarios, dirigentes políticos y militares para legitimar reclamos de cierre de la revisión del pasado o para justificar normativas legales que perseguían tal objetivo (Fabris, 2013b).

Al considerar las intervenciones de Criterio hallamos que no legitimó sus posicionamientos recurriendo a consideraciones de tipo religioso. Por el contrario, la revista insistió en la necesidad de diferenciar el espacio político e intervenir en él aceptando su autonomía. A través del planteamiento de esta diferenciación, Criterio se distinguió frente a la mayoría de los obispos, que equipararon la reconciliación al cierre de la revisión del pasado. Criterio, ante "el doble sentido y el eufemismo" que recurría al valor espiritual de la reconciliación cristiana para no plantear la amnistía, sostuvo que la "sociedad reconciliada" solo se lograría a partir de una decisión política. Consiguientemente se puede decir que, si existió un contrapunto entre la revista y la jerarquía de la Iglesia, no tuvo que ver ni con las interpretaciones del pasado reciente ni con la búsqueda de alternativas para dar un cierre a la cuestión; la diferencia radicó en distintas fuentes de legitimidad para los posicionamientos asumidos. Para Criterio, la clausura de la revisión del pasado respondía a una concepción de la democracia en la que podían convivir las reglas republicanas con pactos y acuerdos que establecieran un espacio obturado a la discusión. Inspirándose en la tradición cristiana o reclamando una "sana prudencia política" se llegaba al mismo punto.

Con respecto a Esquiú, observamos que su apoyo explícito a la experiencia procesista enfrentó a la revista con la necesidad de reubicarse en un

61 Luchía Puig, L. E. (1985, diciembre 22). Que el cielo los juzgue. Esquiú, p. 5. BCN, Buenos Aires. 
escenario desfavorable cuando se produjo el retorno de la democracia. Con el gobierno militar en retirada, fracasado el proyecto político que había seducido al semanario, la integración al nuevo escenario se realizó a partir de un afianzamiento de la identificación como voz oficiosa de la jerarquía. Esta mayor identificación con el Episcopado permitiría recurrir a una fuente de legitimación extrapolítica para reclamar la clausura de la revisión del pasado. Con el retorno de la democracia, la revista construyó una imagen de distanciamiento con respecto a la "violencia guerrillera" y a las FFAA y defendió la búsqueda de "un justo medio" en línea con la teoría de los "dos demonios". Esto condujo a una cierta indefinición política que afectó el vínculo con sus lectores. La posibilidad de sostener este posicionamiento desapareció cuando las denuncias incluyeron a miembros de la Iglesia y la justicia federal avanzó en el procesamiento de los militares. Frente a esta situación, Esquiú defendió la idea de que los comandantes procesados eran "chivos expiatorios" que cargaban con las culpas de la sociedad. Finalmente, la revista se reconcilió con sus anteriores posiciones, aunque es poco probable que ello le permitiera rehacer su vínculo con los lectores.

\section{Referencias bibliográficas}

1. Acha, O. (2000). Organicemos la contrarrevolución: discursos católicos sobre la familia, la reproducción y los géneros a través de Criterio (19281943). En O. Acha y P. Halperín (Comps.) Cuerpos, géneros, identidades. Estudios de Historia de género en Argentina (pp. 135-194). Buenos Aires: Ediciones del Signo.

2. Borrelli, M. (2012). Criterio frente al golpe de Estado de 1976: una apuesta a la salida institucional. En J. Saborido y M. Borrelli (Comps.) Voces y silencios. La prensa argentina y la dictadura militar (1976-1983) (pp. 225-249). Buenos Aires: Eudeba.

3. Bourdieu, P. y de Saint-Martin, M. (2009). La Sagrada Familia. El episcopado francés en el campo de poder. En P. Bourdieu La eficacia simbólica. Religión y política (pp. 91-197). Buenos Aires: Biblos.

4. Conferencia Episcopal Argentina. (1981). Iglesia y Comunidad Nacional. Buenos Aires: Claretiana.

5. De Ruschi Crespo, M. I. (1998). Criterio, un periodismo diferente: génesis y fundación. Buenos Aires: Grupo Editor Latinoamericano.

6. Fabris, M. (2012). Iglesia y democracia. Avatares de la jerarquía católica en la Argentina post autoritaria. Rosario: Prohistoria. 
7. Fabris, M. (2013a). Un proyecto integral para el catolicismo "derrotado". Esquiú y la llegada de Comunión y Liberación. Estudios del ISHiR , 5, 122-135.

8. Fabris, M. (2013b). Perdonar y reconciliarse. La Iglesia católica argentina, el retorno de la democracia y la revisión de las violaciones a los derechos humanos. Secuencia, 85, 67-89.

9. Jesús, L. (2007). Católicos y nacionalistas en los orígenes de la revista Criterio, 1928/1930. Ponencia presentada en las XI Jornadas Interescuelas/ Departamentos de Historia. Tucumán, 19 al 22 de septiembre de 2007, Facultad de Filosofía y Letras, Universidad Nacional de Tucumán.

10. Lida, M. (2015). Estética, cultura y política en la revista Criterio (Argentina, 1928-1936). Nuevo Mundo Mundos Nuevos. Ecole de Hautes Etudes en Sciences Sociales, Débats. Disponible en: http://nuevomundo.revues. org/67968. DOI: 10.4000/nuevomundo.67968

11. Mauro, D. (2008). Las voces de Dios en tensión. Los intelectuales católicos entre la interpretación y el control. Santa Fe, 1900-1935. Signos Históricos, 19, 128-157.

12. Pattin, S. y Schkolnik, I. (2013). El mundo del trabajo y la revista Criterio, un vínculo conflictivo (1966-1979). Itinerantes, 3, 133-152.

13. Pérez López, P. (2005). Católicos y medios de comunicación en España durante el franquismo y la democracia. Un análisis comparativo. En J. Ruiz Sánchez (Ed.) Catolicismo y comunicación en la historia contemporánea (pp. 55-76). Sevilla: Universidad de Sevilla.

14. Rapalo, M. E. (1990). La Iglesia católica argentina y el autoritarismo político: la revista Criterio 1928-1931. Anuario IEHS, 5, 51-70.

15. Rodríguez, A. M. (2003). Cuerpo, familia y género. La revista Criterio, discurso católico en la Argentina de mediados del siglo XX. Anclajes, 7, 201-240.

16. Vezzetti, H. (2002). Pasado y presente. Guerra, dictadura y sociedad en la Argentina. Buenos Aires: Siglo XXI.

17. Zanatta, L. (1996). Del Estado liberal a la nación católica. Iglesia y Ejército en los orígenes del peronismo. Bernal: Universidad Nacional de Quilmes. 